\title{
The effects of sheet spacing on the fatigue life of spot- welded joints
}

\author{
S. Hassanifard ${ }^{1, \mathrm{a}}$, M. Zehsaz ${ }^{2}$, and F. Esmaeili ${ }^{3}$ \\ ${ }^{1,2,3}$ Building No. 8, Faculty of Mechanical Engineering, University of Tabriz, Tabriz, Iran
}

\begin{abstract}
While investigating the fatigue strength of spot-welded joints, the effects of sheet spacing or gap amounts between sheet joints may be considered as one of the most important parameters on the fatigue life duration of the joints. The main goal of the present work is to study the influence of sheet spacing on the fatigue life of 5083-O aluminium alloy spot welded tensile-shear joints. The amounts of sheet spacing are the average values over three measurements of photograph observation of the cut-off surfaces from the nugget centre of the spot-welded joints. The amounts of gap distances between spot weld sheet joints for three different electrode clamping force levels were $0.09 \mathrm{~mm}, 0.11 \mathrm{~mm}$ and $0.13 \mathrm{~mm}$, respectively. The values of notch strength reduction factors have been obtained at all levels of applied loads based on volumetric approach. The fatigue lives of spot welded joints have been obtained according to the volumetric method using the notch strength reduction factors and the available smooth S-N curve of 5083-O aluminium alloy sheets. The results based on the volumetric approach have been compared with the experimental fatigue test data and there is good agreement between numerical predictions and experimental results.
\end{abstract}

\section{Introduction}

Spot welding is widely used for fabricating and joining of metals when the thickness of sheet joints is up to about four millimetres. A very common example of applying the spot welding technique is the metal sheet joining in the automotive industry in which 3000 to 5000 spots are used for every automobile body assembling.

Among a variety design criteria such as yielding, buckling, fatigue, creep and corrosion, fatigue failure is the most frequent mode and the main cause of damage which should be avoided through appropriate design. Although several papers have been published dealing with the fatigue life of spot welded joints [1-7], it seems that because of very complex and maybe unknown mechanical and metallurgical parameters, further attempts are required for better understanding the behaviour of the joints subjected to the repetitive loading.

Some factors which affect fatigue life of spot welded joints can be classified into the following categories; stress concentration factors, residual stresses, material characteristics, welding process parameters (welding time schedule, electric current and electrode clamping pressure), weld quality (weld nugget size, amount of sheet spacing, penetration, indentation) and etc. Among the above

\footnotetext{
a e-mail : hasanifard@tabrizu.ac.ir
} 
mentioned parameters, fatigue strength reduction factor and notch radius effects play important roles with regard to the fatigue life of spot welded joints and need further refinement.

Adib et al. [8] investigated the fatigue life prediction of spot welded joints for different geometries including gap effects between sheet joints. To obtain effective stresses, effective distances and notch strength reduction factors, they plotted the stress distributions along the line fatigue crack opening path-starting from the point susceptible to fatigue crack initiation through the sheet thickness and normal to the loading direction. However, the crack growth morphology results of spot weld tensile-shear joints have been shown that directions of crack propagation are not exactly perpendicular to the loading direction, but they make angles about 75 degrees with respect to the loading direction [9]. A typical propagated fatigue crack in the spot weld tensile-shear joint has been shown in Figure 1.

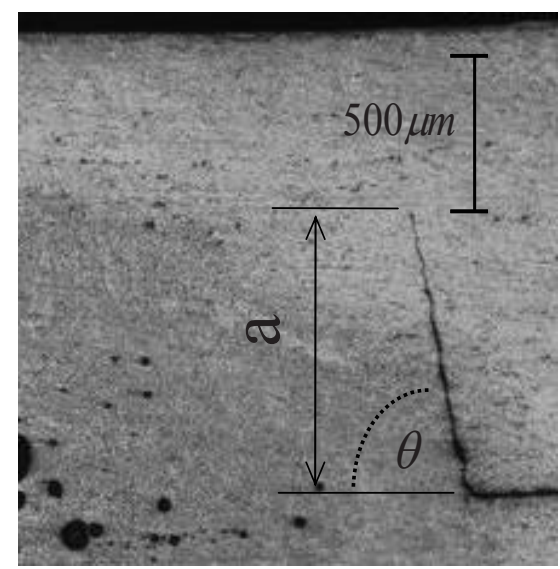

Fig. 1. Propagated fatigue crack at the root of spot weld nugget

Notch radius or sheet spacing effect is a very important parameter which can influence the fatigue life especially in mono spot welded joints [8,9]. Different values of gap between sheets produce different stress distributions near the spot-weld roots, therefore they will affect on fatigue life of the spot welded joints. Although the larger gaps cause to increase slightly the amounts of stresses near the notch roots due to bending effect, as it will be shown in this study, they reduce mean stress and strain range during a complete loading-unloading cycle, therefore according to the modified Morrow's damage equation it can improve the fatigue life of spot welded joint which seems to be in conflict with the statement "the gap effects increases stress values and stress distribution pattern near notch root and produces a lower fatigue life in fatigue analysis of spotwelds" given by Adib et al. [8]. Larger gaps also can reduce notch strength reduction factors which are very important parameters while assessing the fatigue life of the joints, but the stresses rise again because of bending effect. It is worth mentioning that, very small gap distance (nearly zero) between sheet joints increases the stress values because of high stress concentration factor. In this case the gap behaves as a very sharp crack; however the bending effect can be neglected.

The instant at which the fatigue failure is assumed to occur is also of great importance. The fatigue process is usually divided into three phases; crack initiation, crack propagation and final failure. It is appropriate to consider the initial crack at the inner surface of the joint near the root of nugget, but unfortunately these cracks are invisible during fatigue tests.

Pan and Sheppard [10] studied the fatigue life prediction of modified coach peel and tensile-shear spot weld specimens using cyclic strain range method. According to their work, fatigue failure was defined as the occurrence of visible cracks on either outer surface of a specimen. However, experimental crack growth morphology results have revealed that it may take thousands of cycles for crack growth from inner side to the outer side of the joints [11]. 
The objective of the present study is to provide complete information about the effects of notch radius and as a consequence the stress concentration effects on the fatigue strength of the spot welded joints. To this end, the joints with different amounts of notch radius have been considered and fatigue strength reduction factors have been obtained. The volumetric approach has been used to assess the fatigue life of the joints.

\section{Theoretical Background}

The stresses at the notch maybe magnified locally by the stress concentration factor $K_{t}$ a compared with the average nominal stresses in the item. This stress rise will of course be very harmful with respect to fatigue damage, but it can not give directly the effective stress range in fatigue. Therefore, the fatigue strength reduction factor should be introduced.

In the present investigation, the fatigue strength reduction factor will be obtained based on the volumetric approach which proposed by Pluvinage [12]. Two major elements indicate that the fatigue mechanism requires a physical volume to take place; fatigue tests are generally affected by a large scatter and fatigue resistance is influenced by the size of specimen and the relative stress gradient which are dimensional parameters.

This approach leads to a two parameter fatigue initiation criterion, the effective stress and the effective distance. The effective distance is associated with a particular point of the elastic-plastic stress distribution presented in a bi-logarithmic graph. The effective stress corresponds to an average value over this distance of the stress distribution weighted by the distance and the relative stress gradient. A typical elastic-plastic stress distribution near a notch has been shown in Figure 2.

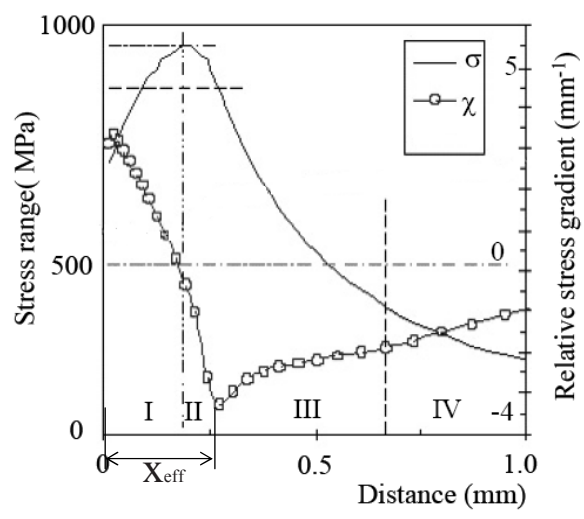

Fig. 2. A typical elastic-plastic stress distribution near a notch [12]

The limit between region II and III can be considered as the effective distance with a high degree of confidence. According to the volumetric approach, fatigue strength reduction factor is given by the following formula:

$$
k_{f}=\frac{1}{X_{e f f} \sigma_{n}} \int_{0}^{X_{e f f}} \sigma_{y y}(x)(1-x \chi) d x
$$

where $X_{\text {eff }}$ is the effective distance, $\sigma_{n}$ is net stress, $\sigma_{y y}$ is the crack opening stress, and $\chi$ is relative stress gradient which is defined as follows: 


$$
\chi=\frac{1}{\sigma(x)} \frac{d \sigma(x)}{d x}
$$

\section{Experiments}

The material employed in this investigation was $1.5 \mathrm{~mm}$ thick $5083-\mathrm{O}$ Aluminium alloy whose chemical composition and mechanical properties have been presented in Tables 1 and 2, respectively.

Table 1. Chemical composition of 5083-O Aluminum alloy.

\begin{tabular}{cccccccc}
\hline \hline $\mathrm{Cu}$ & $\mathrm{Si}$ & $\mathrm{Fe}$ & $\mathrm{Mn}$ & $\mathrm{Mg}$ & $\mathrm{Zn}$ & $\mathrm{Ti}$ & $\mathrm{Al}$ \\
\hline 0.1 & 0.4 & 0.4 & $0.4-1$ & $4-4.9$ & 0.25 & 0.15 & $\mathrm{Bal}$ \\
\hline \hline
\end{tabular}

Table 2. Mechanical properties of 5083-O Aluminum alloy.

\begin{tabular}{ccccc}
\hline \hline $\begin{array}{c}\text { Young's modulus } \\
(\mathrm{GPa})\end{array}$ & $\begin{array}{c}\text { Yield stress } \\
(\mathrm{MPa})\end{array}$ & $\begin{array}{c}\text { Tensile strength } \\
(\mathrm{MPa})\end{array}$ & $\begin{array}{c}\text { Elongation } \\
(\%)\end{array}$ & $\begin{array}{c}\text { Poisson's ratio } \\
(\mathrm{v})\end{array}$ \\
\hline 70 & 145 & 290 & 22 & 0.33 \\
\hline \hline
\end{tabular}

Three types of spot weld tensile-shear specimens with three different electrode clamping force were produced for this investigation. Details of RSW process parameters and welding attributes are presented in Table 3 .

Table 3. Resistance spot welding process parameters and welding attributes of all spot weld specimens.

\begin{tabular}{cccc}
\hline \hline $\begin{array}{c}\text { Electrode force } \\
(\mathrm{kN})\end{array}$ & $\begin{array}{c}\text { Electric Current } \\
(\mathrm{kA})\end{array}$ & Nugget diameter $(\mathrm{mm})$ & Gap distance $(\mathrm{mm})$ \\
\hline 2.5 & 20 & $7.48(6.10 \sqrt{t})$ & 0.09 \\
\hline 3 & 20 & $7.53(6.14 \sqrt{t})$ & 0.11 \\
\hline 3.5 & 20 & $6.08(4.96 \sqrt{t})$ & 0.13 \\
\hline \hline
\end{tabular}

The configuration of spot weld tensile-shear specimen has been shown in Figure 3.

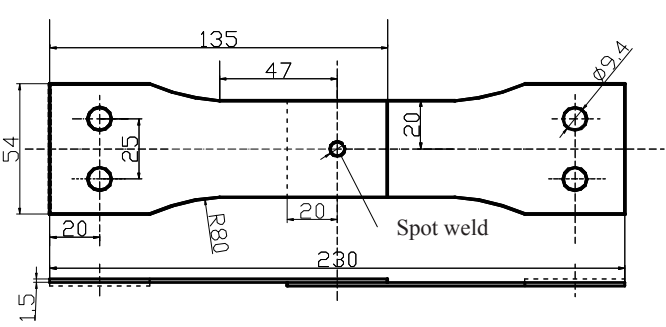

Fig. 3. Configuration of tensile-shear spot weld specimen 
Fatigue test results for three different types of spot welded joints have been shown in Figure 4.

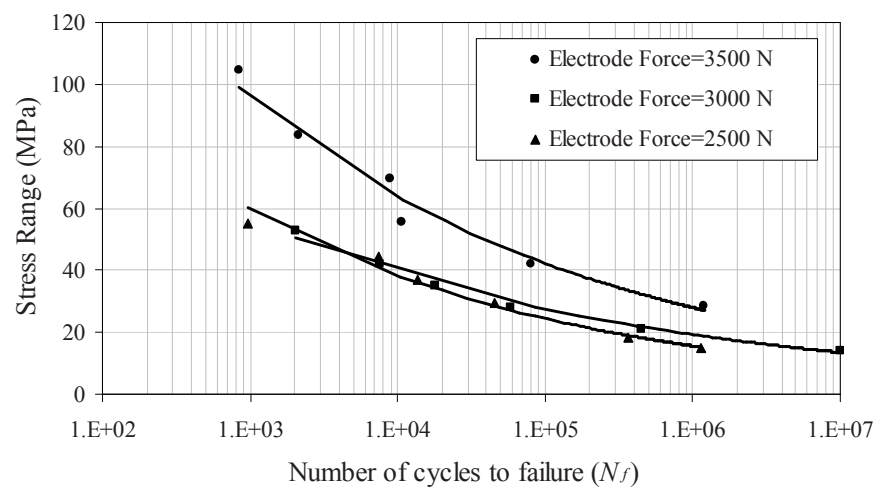

Fig. 4. Fatigue test results for three different types of spot welded joints (Gaps are equal to $0.13,0.11$, and $0.09 \mathrm{~mm}$, respectively)

As it can be seen in Figure 4, increasing the electrode force from $3000 \mathrm{~N}$ to $3500 \mathrm{~N}$ despite of decreasing in the weld nugget, improved the fatigue life of the joints significantly, however increasing the electrode force from $2500 \mathrm{~N}$ to $3000 \mathrm{~N}$ had no major impact to improve the fatigue strength of the joints. Details of all experimental tests are available in the previous paper by Hassanifard et al. [9].

\section{Finite Element Analysis}

To obtain the fatigue life of the joints with three different gaps listed in Table 3 and also notch strength reduction factors, three dimensional models of the joints were simulated using ANSYS finite element software. Structural 8-node element was used to perform the non-linear analysis for obtaining the amounts of stress and strain values near the roots of nuggets. To obtain more realistic and mesh insensitive results, sub-modelling technique was applied. Figure 5 show the finite element meshed model and sub model of the joints in different views.
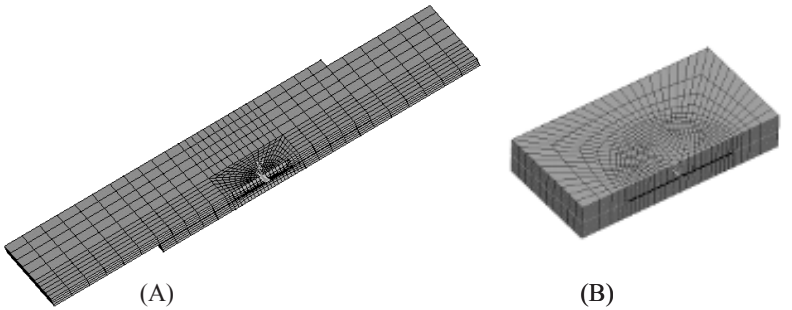

(B)

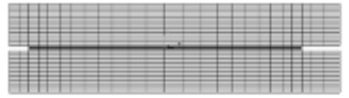

(C)

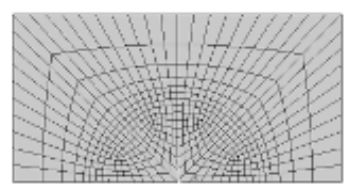

(D)

Fig. 5. Finite element meshed model and sub model of the joints in different views; (A) Isometric view of the joint, (B) Isometric view of sub-model, (C) Front view of sub-model, (D) Top view of sub-model 
The amount of sheet spacing has been divided into six elements and the minimum size of the elements at the root of nugget was $0.015 \mathrm{~mm}$.

Non-linear analyses for different loads at the approximate range of $30 \%-80 \%$ of static fracture load were applied on the models and the values of equivalent mean stress and strain range were obtained during one complete loading-unloading cycle. The elastic-plastic stress distributions and relative stress gradients along the crack path starting from the roots of nuggets have also been extracted.

\section{Results and Discussion}

Figure 6 show the crack opening stress distributions and relative stress gradients along the crack paths from the nugget roots for applying $50 \%$ of static fracture load for spot weld specimens with different gaps between their sheets. The values of notch strength reduction factors have been obtained at all levels of loads based on volumetric approach. As it can be seen in Figure 6, the maximum stresses do not occur at the roots of nuggets.

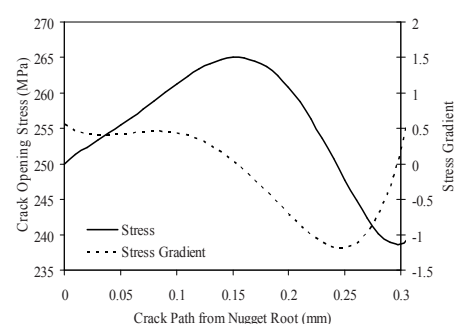

(A)

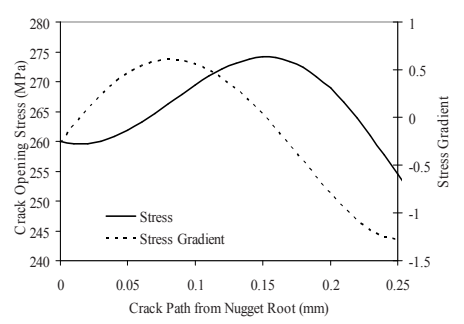

(B)

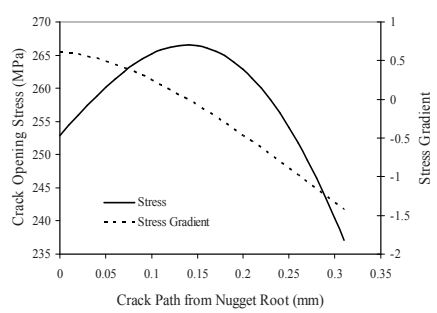

(C)

Fig. 6. Crack opening stress distribution and relative stress gradient along the crack path from the nugget root of spot weld for applying $50 \%$ of static fracture load; (A) gap $=0.09 \mathrm{~mm}$, (B) gap $=0.11 \mathrm{~mm}$ and (C) gap $=0.13 \mathrm{~mm}$

Loading data, mean stress, strain amplitude and notch strength reduction factors for spot weld specimens having three different gaps compared with the case that gap has not been simulated between sheet joints, are listed in Table 4.

Table 4. The values of mean stress, strain range and notch strength reduction factor for all spot weld specimens in different levels of applying loads.

\begin{tabular}{|c|c|c|c|c|c|c|c|c|c|}
\hline & \multicolumn{3}{|c|}{ A-Type $(\mathrm{Gap}=0.09 \mathrm{~mm})$} & \multicolumn{3}{c|}{ B-Type $(\mathrm{Gap}=0.11 \mathrm{~mm})$} & \multicolumn{3}{c|}{ C-Type $(\mathrm{Gap}=0.13 \mathrm{~mm})$} \\
\hline $\begin{array}{c}\text { Load } \\
(\mathrm{kN})\end{array}$ & $\sigma_{m}(\mathrm{MPa})$ & $\Delta \varepsilon$ & $K_{f}$ & $\sigma_{m}(\mathrm{MPa})$ & $\Delta \varepsilon$ & $K_{f}$ & $\sigma_{m}(\mathrm{MPa})$ & $\Delta \varepsilon$ & $K_{f}$ \\
\hline 1.6 & 108.62 & 0.0028 & 9.0 & 103.4 & 0.0023 & 8.9 & 101.34 & 0.0022 & 8.9 \\
\hline 2 & 10.65 & 0.0048 & 8.1 & 108.1 & 0.0045 & 8.1 & 106.03 & 0.0042 & 8.0 \\
\hline 2.4 & 119.82 & 0.007 & 6.5 & 118.5 & 0.0067 & 6.4 & 114.58 & 0.0062 & 6.3 \\
\hline 2.8 & 129.03 & 0.0091 & 6.0 & 128.4 & 0.0086 & 5.9 & 125.36 & 0.0082 & 5.8 \\
\hline 3.2 & 143.53 & 0.0141 & 5.3 & 141.6 & 0.0138 & 5.2 & 141.54 & 0.0131 & 5.1 \\
\hline
\end{tabular}

The results indicate that increasing the gap distance between sheets decrease the values of mean stress, strain range, and notch strength reduction factor. 
Figure 7 shows the stress range versus fatigue lives for all spot weld specimens obtained from the volumetric approach. As it can be seen in this Figure, smaller gaps predict the smaller lives for the joints, because the small distance can behave as a sharp crack, hence the stresses near the root of nugget increases because of higher amounts of stress concentration factors. When the gap distance become larger, the amount of stresses increase slightly because of bending effects in tensile-shear joints, however the amounts of stress concentration factor and notch strength reduction factors which have been obtained based on the volumetric approach decrease significantly, therefore they produce the higher fatigue lives. Figure 7 also show very good agreement and similar pattern with S-N curve shown in Figure 4.

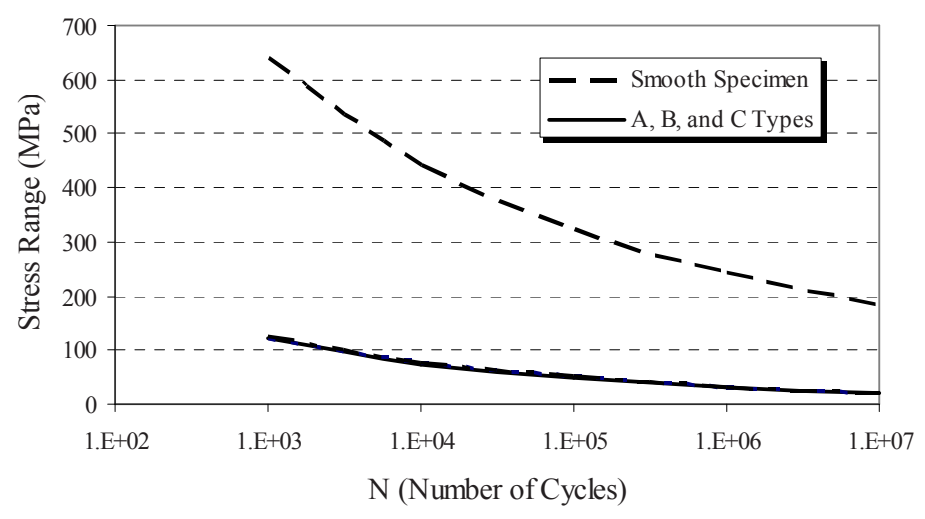

Fig. 7. Stress range versus predicted fatigue lives based on the volumetric approach for all spot weld specimens

\section{Conclusions}

The influence of sheet spacing in resistance spot welding process and also the notch strength reduction factor on the fatigue life of 5083-O aluminium alloy spot welded tensile-shear joints has been investigated in this study.

It would appear that increasing gap between sheets increase the amounts of stresses at the notch roots because of bending effects but it has been shown that mean stress and strain range in a complete loading-unloading cycle and also the values of notch strength reduction factor decrease with rising sheet spacing amounts.

Sheet spacing appeared to have a more considerable role in fatigue performance of spot welded joints. Existing a notch with a large radius of its root is the most important reason to have a longer fatigue life of the joints which have produced by higher electrode forces. Also, the effects of notch discontinuity as the stress concentration areas play more important role in either low cycle or high cycle fatigue regimes. The results based on the volumetric approach have been compared with the experimental fatigue test data and there is relatively good agreement between numerical predictions and experimental results. 


\section{References}

1. X. Long, and S. K. Khanna, Fatigue properties and failure characterization of spot welded high strength steel sheet, International Journal of Fatigue, 29, 879-886 (2007).

2. J. Linder, A. Melander, M. Larsson, and Y. Bergengren, Fatigue design of spot-welded austenitic and duplex stainless sheet steels. Fatigue \& Fracture of Engineering Materials \& Structures, 21, 673-686 (1998.

3. R. Spitsen, D. Kim, B. Flinn, M. Ramulu, and E. T. Easterbrook, The effects of post-weld cold working processes on the fatigue strength of low carbon steel resistance spot welds. Journal of Manufacturing Science and Engineering, Transactions of the ASME, 127, 718-723 (2005).

4. A. Gean, S. A. Westgate, j. C. Kucza, and J. C. Ehrstrom, Static and fatigue behavior of spot welded 5182-O aluminum alloy sheet. Welding Journal, Vol. 78, No. 3, pp. 80-86 (1999).

5. X. Sun, E. V. Stephens, R. W. Davies, M. A. Khaleel, and D. J. Spinella, Effects of fusion zone size on failure modes and static strength of aluminum resistance spot welds. Welding Journal, Vol. 83, No. 11, pp 308-318 (2004).

6. B. H. Chang, and Y. Zhou, Numerical study on the effect of electrode force in small-scale resistance spot welding. Journal of Materials Processing Technology, 139, 635-641 (2003).

7. K. Ni, and S. Mahadevan, Strain-based probabilistic fatigue life prediction of spot-welded joints. International Journal of Fatigue, 26, 763-772 (200).

8. H. Adib, J. Gilgert, and G. Pluvinage, Fatigue life duration prediction for welded spots by volumetric method. International Journal of Fatigue, 26, 81-94 (2004).

9. S. Hassanifard, M. Zehsaz, and K. Tohgo, The effects of electrode force on the mechanical behavior of resistance spot-welded 5083-O aluminum alloy joints. Journal of Strain, DOI: 10.1111/j.1475-1305.2008.00554.x. (2008).

10. N. Pan, and S. Sheppard, Spot welds fatigue life prediction with cyclic strain range. International Journal of Fatigue, 24, 519-528 (2002

11. S. Hassanifard, M. Zehsaz, K. Tohgo, and T. Ohguma, The prediction of fatigue crack initiation life in spot welds. Journal of Strain, Vol. 45, No. 6, 489-497 (2009).

12. G. Pluvinage, Fracture and Fatigue Emanating from Stress Concentrators. Published by Springer, ISBN 1402016093, 9781402016097 (2003).

13. Y. L. Lee, J. Pan, R. Hathaway, and M. Barkey, Fatigue testing and analysis (Theory and Practice). Elsevier Inc., Amsterdam (2005). 